Author: Piotr Cichosz

Title of article: „Innowacyjne narzędzia i technologie obróbki skrawaniem” ("Innovative machining tools and technologies")

Mechanik, Vol. 91, No. 10 (2018): pages 794-802

DOI: https://doi.org/10.17814/mechanik.2018.10.133

\title{
Innovative machining tools and technologies
}

\author{
Innowacyjne narzędzia i technologie obróbki skrawaniem
}

\section{PIOTR CICHOSZ *}

\begin{abstract}
Modern tools and innovative technologies used in machining are presented, and potential development directions of these manufacturing techniques are described. Particular attention is drawn to anti-wear tool materials and coatings, as well as structural elements of tools and machining strategies which strongly affect the broadly understood manufacturing efficiency.

KEYWORDS: machining, tools, technologies, innovations
\end{abstract}

Progress in machining technologies has always been taking place in a more evolutionary than revolutionary way. Even when cutting-edge tool materials, such as high-speed steels, sintered carbides and tool ceramics, that allowed to significantly intensify shaping performance, their implementation in industry took place gradually over the years.

Similarly now, and not only in relation to new or constantly improved tool materials, protective coatings applied to blades, but also new technologies such as: dry machining, minimized lubrication (MQL), trochoidal machining, complete machining, at high speeds, highly productive, hard or high feeds [1-3, 5-7, 19].

The article is devoted to selected technologies that allow to intensify cutting efficiency.

\section{Tool materials and protective coatings}

Tool material plays a key role in machining because it determines the ability to process specific materials, greatly affects the intensity of blade wear and productivity, determines production costs, etc. Furthermore, it affects the ease of forming blades and attaching them to the tool body and resistance for difficult cutting conditions (mechanical and thermal shocks).

Within tool materials no breakthroughs have been observed in recent years. Work is ongoing to improve known species.

The last turning point in the improvement of high-speed steel was the initiation of its production by powder metallurgy. The lack of segregation of hard carbide fractions in this technology allowed to increase their amount in the alloy, which resulted in a slightly higher hardness of steel than could be achieved by traditional methods of its production by means of casting and re-shaping.

\footnotetext{
* Prof. dr hab. inż. Piotr Cichosz (piotr.cichosz@pwr.edu.pl) Katedra Obrabiarek i Technologii Mechanicznych, Wydział Mechaniczny Politechniki Wrocławskiej
}

A further increase in the capacity of high-speed steel machining tools is today mainly attributed to anti-wear coatings.

Sintered carbides are still the basic tool material. About $50 \%$ of the tools are made of it. This material in an optimal way, like no other, combines such features as abrasion resistance and relatively high durability.

Over a dozen years ago, ultra-fine-grained carbides with a grain size of approx. $0.3 \mu \mathrm{m}$ were obtained. This structure contributed to a significant increase not only in the hardness of the sinter, but also in its bending strength - until that time they were contradictory features. As in the case of highspeed steels, no significant progress has been made in the development of sintered carbides in recent years.

A similar view can be expressed with reference to oxide, mixed and nitride ceramics [3, 9-10, 13, 15-16]. Work is ongoing to increase the resistance of these materials to brittle fracture, thermal shocks, as well as their bending strength. However, achievements in this field are moderate.

Blades in the form of removable ceramic tiles have been used for a very long time. However, the use of these tool materials in monolithic tools such as drill bits or end mills is difficult due to their disadvantages and poor behavior at low cutting speeds as are the case with tools with small diameters or in the vicinity of the tool rotation axis. Increasing the bending strength and fracture toughness of ceramic materials resulted in the offering of end mills from these materials $[9,13]$.

Fig. 1 shows a ceramic milling cutter for machining nickel-based superalloys. It is offered with diameters in the range of $6 \div 12 \mathrm{~mm}$.

It also failed to significantly improve the cutting properties of super-hard materials. The mainstream of development is work related to the improvement of binding material of diamond grain or regular boron nitride. There are a dozen or so sintered species from these materials. They differ in the size of small, medium or large grains $(\sim 2 \mu \mathrm{m}, \sim 10 \mu \mathrm{m}, 25$ $\mu \mathrm{m})$ and mixed fractions, e.g. large and small grains, which allows for a higher concentration of hard fractions in the sinter. The basic binder is cobalt, which has very good wetting properties of the grain, and also a fairly high melting point.

Regular boron nitride (BN) is almost twice as resistant to high temperatures (up to about $1400^{\circ} \mathrm{C}$ ) than diamonds. To use this, not only cobalt is used for BN sintering, but also $\mathrm{Al}_{2} \mathrm{O}_{3}$ and $\mathrm{TiCN}$ ceramics $[15,16]$. It happens that the concentration of BN grains in the sinter is less than $50 \%$. Because sintered BN has several times higher bending strength than diamond sinters, this material is therefore 
suitable for monolithic indexable inserts, and not only for the corners themselves (as is the case with diamond sinters).
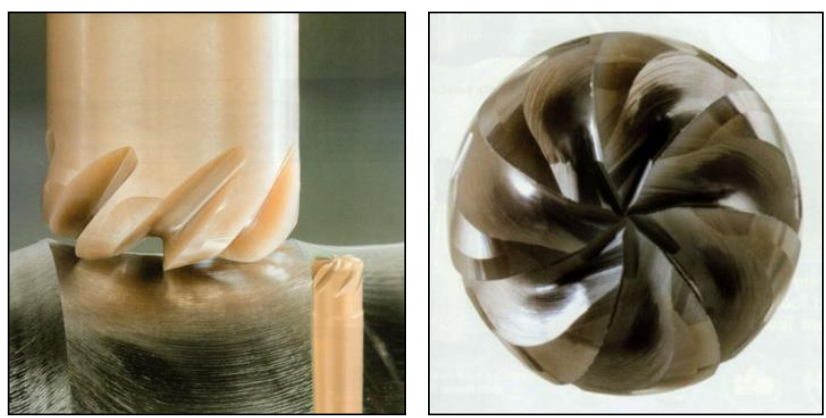

Fig. 1. Ceramic mandrel milling cutter (Iscar)

Some opportunities to extend the use of diamond for machining are associated with attempts to return to the blades from its single crystals. This is the result of dynamically developing methods of diamond synthesis. Currently, artificial diamonds of up to $10 \times 10 \mathrm{~mm}$ are offered [3].

Every few months, new or thoroughly modified versions of anti-wear coatings applied to the blades appear. High speed coatings or for hard machining - i.e. under very high cutting temperatures - withstand temperatures of $1300^{\circ} \mathrm{C}$. This allows you to successfully process hardened materials with sintered carbides.

Diamond coatings applied on sintered carbide blades have been used for many years. Recently, they have also appeared in the version in which many layers of ultra-finegrained and fine-grained diamond are alternated. This increases the mechanical properties of the entire coating and allows you to increase its thickness.

Various sources indicate that about $65-80 \%$ of all tools used in mass production are coated. This also applies to sharpen tools that are repaired. The coating of blades from regular boron nitride and ceramics is used. Attempts are made to coat carbide blades with coatings of regular boron nitride.

\section{Minimizing the use of tool materials}

Most of the tool materials are composed of cobalt, mainly in the form of a binder. In recent years, there has been a sharp increase in the demand for this material, primarily due to the use of this element in the production of batteries and accumulators. The prices of cobalt products reach a dizzying level. Hence the need:

- constructing tools with the lowest possible content of tool material, but fulfilling their role in effective machining,

- use of multiple working corners in removable folding tool boards,

- using plates fixed through a hole,

- ensure a strong, secure attachment of the exchangeable blade, so that even in the case of small dimensions, the blade can be cut with high parameters,

- use of replaceable blades in the spindle tools with smaller and smaller diameters (fig. 2), which until now were performed as solid carbide monolithic tools,

- use of solid tips made of super-hard materials in tools with small dimensions, even on the order of $1 \mathrm{~mm}[3,9,12$, 13-17].

Fig. 2 presents folded mandrel tools, alternative to solid carbide tools. These are tools with extremely small blades. Thanks to them, the amount of tool material needed to carry out the machining is many times smaller. Interchangeable blades require special construction solutions for the fixing and fixing elements of these blades to ensure high repeatability of positions and secure fixing.

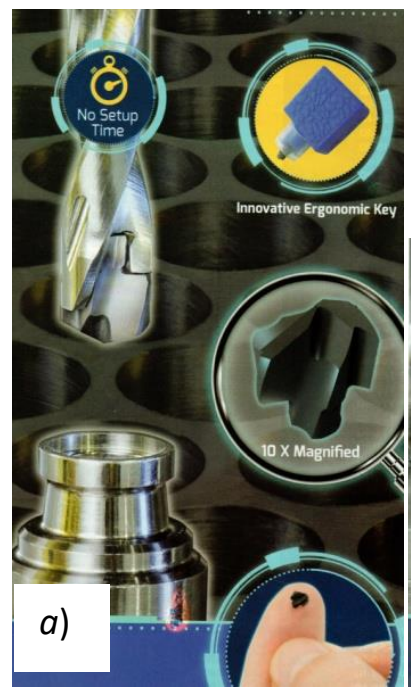

Fig. 2. Folding tools with extremely small blades: a) drills with heads, from diameters $\varnothing 4 \mathrm{~mm}, \quad \mathrm{~b})$ indexable end mills, from Ø8 $\mathrm{mm}$ (Iscar)
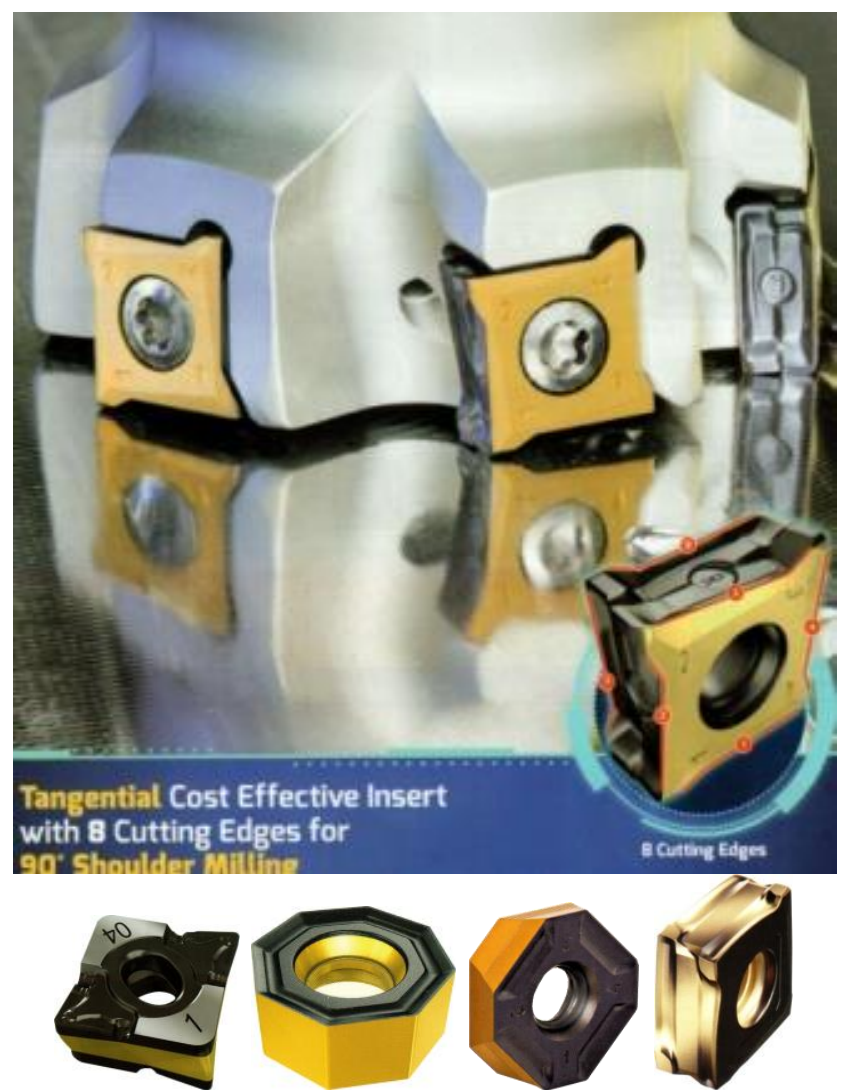

Fig. 3. Examples of indexable inserts ensuring maximum number of blades in relation to the volume of tool material (Iscar, Mitsubishi)
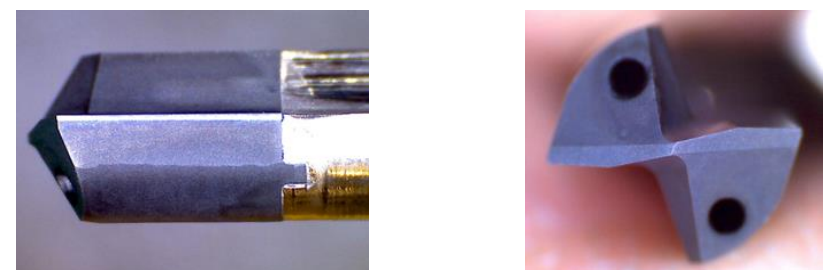

Fig. 4. $2.5 \div 6 \mathrm{~mm}$ drill bit with a sintered diamond tip directly scorched to the tool body (Mapal) 
Fig. 3 presents exemplary blades of milling heads, in which they tried to use as many cutting edges/corners as possible while using the tool material as small as possible. These tiles, despite the so-called positive geometry is made in a two-sided version and they have 16 active corners. The weight of the tool material further reduces the mounting hole.
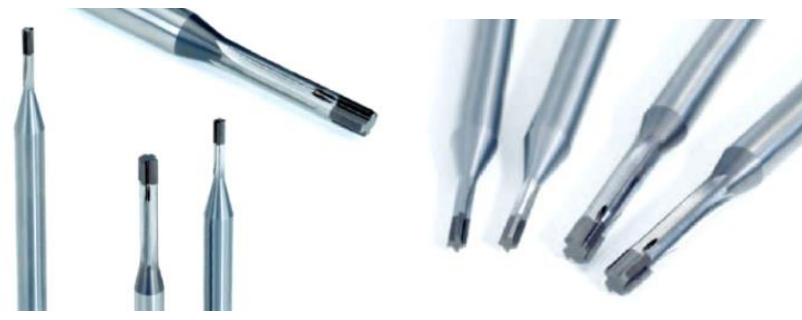

Fig. 5. BN reamers for machining small holes (Mapal)

\section{Rounding of cutting edges}

Until recently, the prevailing view was that the sharper the edge, the more favorable the cutting properties of the tool. Currently, most of the cutting blades have more or less rounded edges with a radius of several to several dozen micrometers. Only diamond blades and for processing soft and composite materials have sharp edges.

Edge rounding, obtained by abrasive machining, e.g. polishing, brushing, abrasive blasting, can significantly extend the tool life $[4,9,11]$. That is why many machines and devices designed for this purpose appeared [4].

\section{Assembly tools}

In the development of team tools, two main directions can be distinguished. The first of these is to increase the scope of modularity. From the ready components, usually with standardized blades, even very complex tools are assembled, and only the corps are constructed. They may not be precisely made, because the precise positioning of the tool blades most often ensures the adjustment of the elastically deformed elements of the inserts. Such flexibility favors the effective use of this group of tools also in the production of ever shorter series of products.

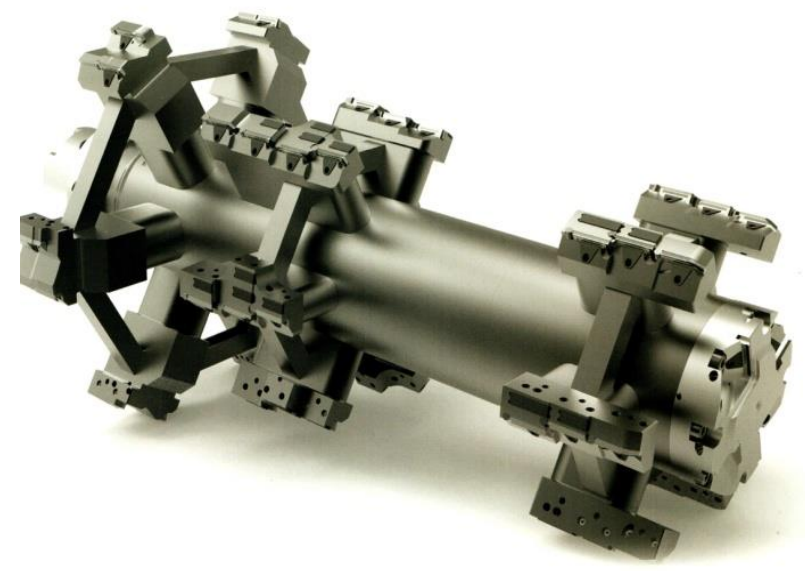

Fig. 6. Precision multi-stage drill bit with light construction for machining large openings (Mapal)

The second trend in the development of team tools is based on the desire to reduce their mass, especially in the case of large tools. Lightweight, openwork, often welded construction allows for the team to process ever larger objects and use standard manipulators for automatic tool changing. The reduction of the mass of tools, not only the team ones, can be achieved by using lighter materials in the production of bodies. Milling heads, e.g. made of aluminum alloys, are available today. Some of the tools of such companies as Mapal and Gühring have bodies made of titanium alloys and composite materials.

Fig. 6 shows a drill for team machining of large-size multistage openings. The construction of this tool was based on a welded body. It is $700 \mathrm{~mm}$ long and has over 40 blades.

Fig. 7 shows tools with a light structure:

- boring bodies made of carbon fiber reinforced composite; the diameters of these tools can reach values in the range of $500 \div 3500 \mathrm{~mm}$,

- tool holders with an openwork design (e.g. made with the use of a generative technique $-3 D$ printing).

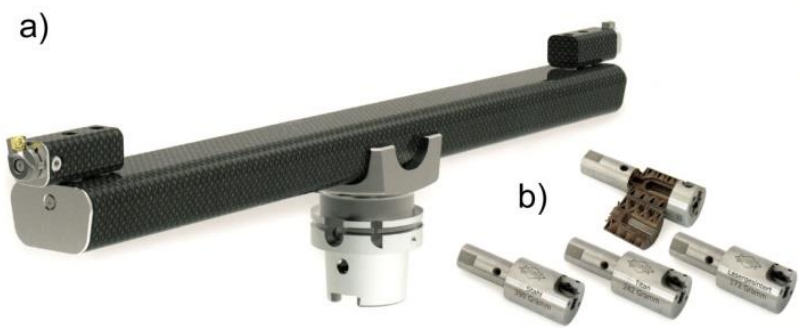

Fig. 7. Lightweight tools: a) boring bar with composite body, b) openwork tool holder made by generative technique (Mapal)

\section{Controlled and mechatronic tools}

The task of controlled and mechatronic tools is to support and supplement the capabilities and accuracy of shaping that machine tools [2] have. It is noticed the gradual continuous development of the construction of such tools in the direction of supporting their capabilities offered by electronics and IT systems for data transmission and processing. Modern mechatronic tools easily integrate with control systems of CNC machine tools and their accessories. Wireless control of multiple tools is applied using a single integrated system operating in the Bluetooth system [2, 11]. There are many additional features that make the tools more supervised and less vulnerable to interference that may occur in the production process.

Work is underway to increase the machining accuracy by means of elastic deformation correction of the OUPN system. Current capabilities of measurement systems, dynamic signal processing and quick reactions of actuators correcting deformations of mechanical system components give hope that not only can be obtained effective correction of their random, static deformations, but also actively react to dynamic changes, including vibration damping $[2,11,12]$.

\section{Supporting cutting with machining fluids}

For some time now, two approaches have been developed to support cutting of machining fluids. Over a dozen years ago, there was a tendency to use dry machining and, where the quality of shaped surfaces required it, the so-called Minimized lubrication (MQL) of the cutting zone by means of oil mist.

Such an approach was justified by the high costs of using machining fluids (in many cases exceeding the tooling costs), as well as significant costs of utilization of these liquids, health, environmental protection, etc. These tendencies were favored by avoiding significant thermal 
shocks that could occur due to cutting development with high speeds and machining of materials in hardened condition. These treatments are accompanied by high temperatures and the use of classical cooling tools could lead to thermal cracking in sensitive tool materials.

Despite the undoubtedly beneficial effects, especially economic, dry machining or MQL, it turned out that in some cases machining in difficult conditions works well in reverse, namely directing the high pressure coolant stream directly under the chip and tangentially to the surface. In this way, a much more intensive cooling and lubrication is achieved, a better quality of the surface to be machined, better grinding and chip evacuation and less tool wear.

This approach also has disadvantages, which include the need to use high-pressure hydraulic systems supplying the treatment zone with cooling and lubricating media. These systems must be efficient, safe and tight in spindle conditions rotating at high speed, automatically exchanged tools, fast moving supports, etc. In such applications, special adapters and tooling systems are used to attach tools in turrets and lathes, as well as systems supplying fluids through rotating spindles, holders and holders, ensuring tightness and protecting the environment from splashes and aerosol formation. Almost all modern modular tool systems and tools allow you to feed machining fluids along the tool axis, through subsequent modules, directly to the cutting zone.

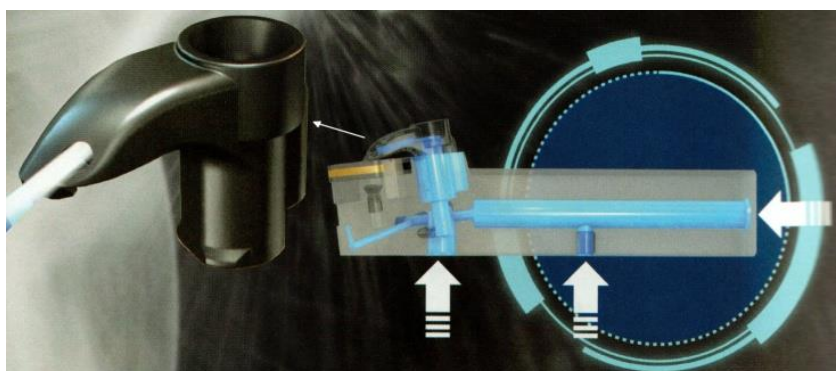

Fig. 8. Methods of supplying coolant to the knife holder and a blade clamping blade with a nozzle located in it (Sandvik)

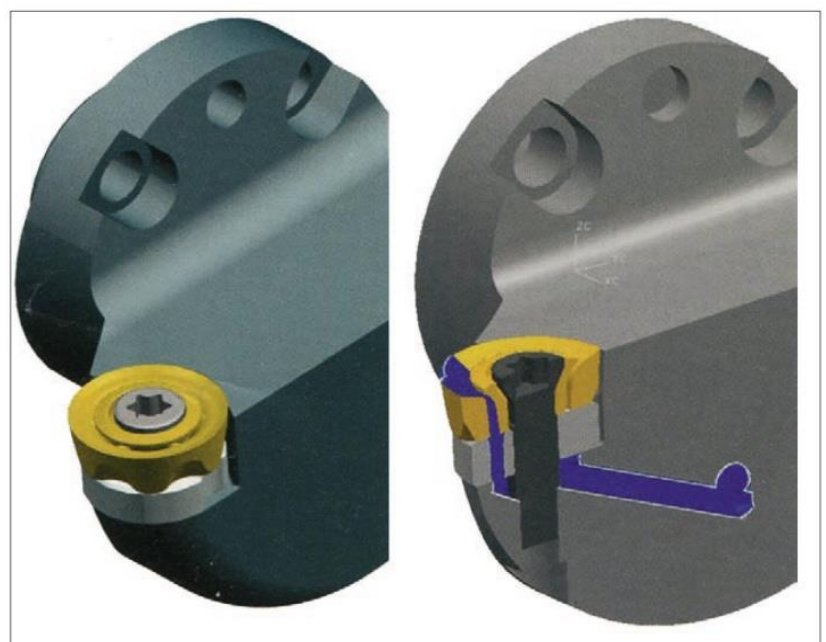

Fig. 9. Way of supplying coolant to the cutting zone through a cutting blade (Kennametal)

Cooling systems with pressure in the range of $50 \div 60$ bar become the standard. Pressure systems of 150 are already being offered, and up to 600 bars are predicted. However, even smaller pressure ranges mean that the supply of liquid for the chip effect causes a "hydraulic wedge" effect, which quite effectively not only intensifies heat removal and reduces friction between the chip and blade working surfaces, but also contributes to the formation of a more favorable, chipped form of chips. It also allows you to increase the optimal cutting speed by approx. $30 \%$.

Traditional cooling by pouring the cutting zone from above - simple and cheap in use - due to its low efficiency in the future will lose its significance even more.

Fig. 8 shows the possibilities of feeding the tool with a coolant and a nozzle, e.g. placed in the clamp holding the interchangeable blade, directing the coolant stream directly under the chip.

An interesting solution for providing chip coolant, while cooling the inner blade and support plate, was proposed by Kennametal in a turning tool made in Beyond Blast technology (fig. 9).

Many tool companies stress the precise supply of coolant where it is needed most. Due to this, the effectiveness of its impact increases and it is possible to reduce the expenditure. Especially in tools with narrow blades, e.g. chisels (fig. 10a) it is necessary to make technologically difficult, long and complex channels in the frames' frames. However, providing machining liquids in such an intensified manner ensures much more effective cooling and lubrication of the hard-to-reach place in which the blade works, extends its durability and facilitates the evacuation of chips (fig. 10b).

a)

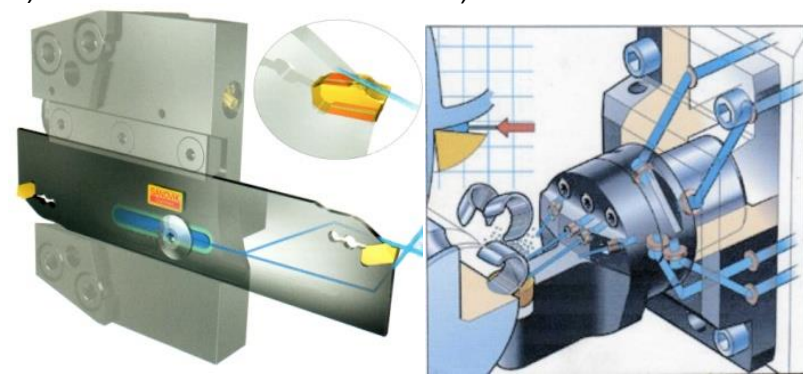

Fig. 10. Different coolant supply systems directly to the cutting zone (Sandvik)

\section{Forming composites}

There is a strong tendency towards the increasing use of composite materials, not only in the aviation industry and the production of sports goods, but wherever there is a strong pressure to use materials with the best ratio of mechanical properties to mass.

The variety of composites is growing. Unfortunately, the workability of these materials worsens most often with increasingly favorable mechanical properties. Composites, of which the matrix itself is reasonably sufficiently machinable - e.g. polymeric materials, resins, light metals require blades with a relatively large positive angle of attack. However, the reinforcement of these materials, due to their high strength and hardness, is most advantageously shaped with blades with a different geometry, with a negative angle of attack. In the processing of such composites, preference is therefore given to sintered diamond blades or sintered carbides with diamond coatings. These materials with positive geometry retain quite good abrasion resistance.

Another problem that occurs during the processing of composites, especially those with a polymer matrix, is delamination. It is internal, parallel to the surface delamination of the composite and fraying and appearance 
of burrs on the edges of the work surfaces. This phenomenon is particularly evident when drilling holes.

In aircraft constructions, riveting is still the most effective joining technique. It requires the execution of hundreds of thousands of holes, and in assembly conditions on largesize constructions that can not be mounted on a machine tool. The holes must be made without any defects, especially internal delaminations difficult to identify. To prevent them, many solutions are used, e.g.:

- Significantly decreases the tip angles of drill bits to approx. $90^{\circ}$ to change the direction of forces generated at the edges - from close to the axis to more radial. This reduces the bending moment of trousers of the composite layer, reduces the tendency to delaminate and improves the quality of the edge of the hole, especially at its outlet. However, in this method the time of getting the drill into the material and leaving it is longer.

- Significant shear correction is applied, decreasing the axial force, which has a dominant role in delamination of the underlying composite layers during the drill's investigation to the bottom of the hole.

- Orbital drilling or circular milling is used, the kinematics of which is similar (fig. 12). These treatments differ only in the tool. In addition to other advantages, these hole patterns provide lower thermal load on the wall of the hole, better chip evacuation and excellent edge quality at the inlet and outlet of the holes.

Many devices/drills have been designed for orbital drilling, providing a stepless, mechanical adjustment of the eccentric value, thanks to which the same tool can be used to shape holes with different diameters. These devices can be operated manually, mounted on robot arms or as machine tools in production lines. When the workpiece is mounted and machined on a CNC machine tool, the circulation movement can be given from the control level.

In traditional drilling kinematics, you can improve the quality of holes drilled in composites by modifying the tool geometry. To limit the chipping and burrs on the inlet and outlet of the hole in composites with a high carbon fiber content, the drill edges can be shaped as shown in fig. 11 . In order to prevent delamination of the composite with a high content of resins, the shear should be corrected (fig. $11 b$ ) and the double-cone geometry should be used (fig. 11a). Sharp corners on the outer edge (fig. 11c) are supposed to reduce burrs on the inlet and outlet of the hole. a)

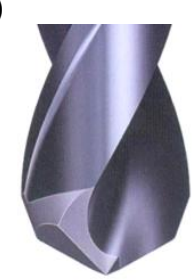

b)

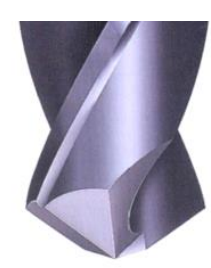

c)

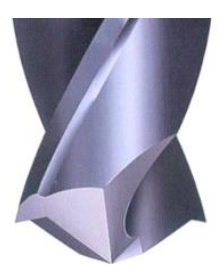

Fig. 11. Examples of drill geometry correction for improving the quality of holes made in composites (Sandvik)

Traditional milling cutters, especially mandrels, have spirally arranged side cutting edges, so that the entry of the blades into the material and exit from it does not generate vibrations that degrade the working conditions. The negative side of the helically arranged edges is the formation of the axial force component. When processing composites, this may lead to shredding of the edges, and in extreme cases - to delamination of layers from the side on which the axial force acts.

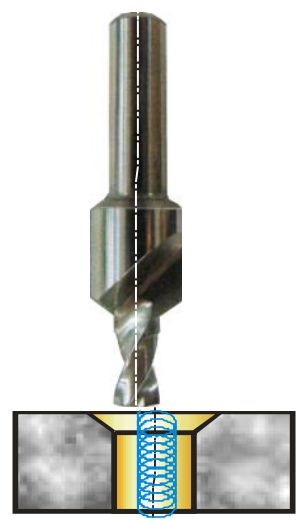

Fig. 12. Diagram of circular forming of holes

To prevent this, the cutting edge is also made as a bolt, but with a stepped construction (fig. 13). This ensures gentle entry of the edge into the material and exit from it, without the appearance of an axial force. However, such a tool construction is much more complicated than classic milling cutters.

The shaft cutter, $\varnothing 10 \mathrm{~mm}$ in diameter, with a diamond coating for processing composites with fiberglass (GFRP) and carbon (CFRP) reinforcements used in aircraft structures, is shown in fig. 13.

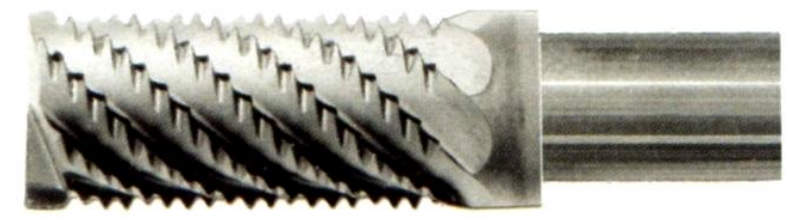

Fig. 13. End mill with diamond coating with stepped edges, for processing composite materials (Prototype-Werke)

Shank cutters with a variable angle of inclination during machining press the outer layers of the composite against each other, which prevents it from delaminating (fig. 14.)

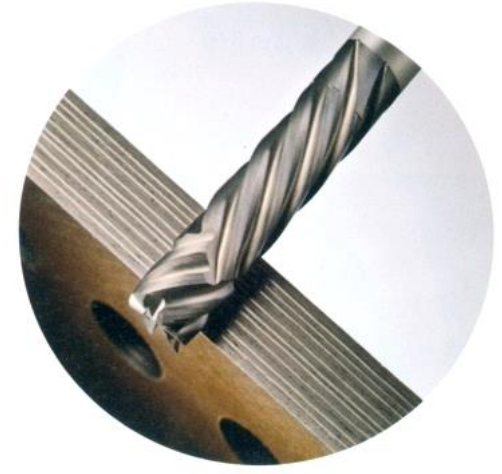

Fig. 14. End milling cutter with variable angle of inclination for processing composites (Sandvik)

The composites in which the matrix is ceramics exhibit extremely good mechanical properties, especially when it comes to hardness at high temperatures. Not only fibers or particles strengthening these composites, but also the matrix has a very strong abrasive effect on the cutting blades. Practically, it prevents the shaping of these materials by machining. However, abrasive machining is very expensive and inefficient.

Attempts to use laser treatments and high-energy waterabrasive jet have a very limited range, because they do not allow for the transmission of complex shapes with high accuracy. Therefore, tools and technologies are being sought for shaping these composites. 


\section{Shaping of gears}

Several tendencies have been observed in shaping the gears in recent years. Folding tools - high performance worm and disc milling cutters for envelope machining - are increasingly being used - and a number of designs have been introduced with interchangeable blades in the shape tools.

Interchangeable carbide blades do not require costly and time-consuming sharpening and re-coating, which is usually done by an external company. This allows you to reduce costs, as well as to increase machining efficiency through the use of larger, optimal cutting parameters and shorter retooling time of the machine. In this way, the advantages of folding tools for milling cutters have been successfully transferred.

Fig. 15a presents a folded screw cutter, and fig. 15b shows a segmental structure of such a tool, allowing the joining of tools of various widths. a)

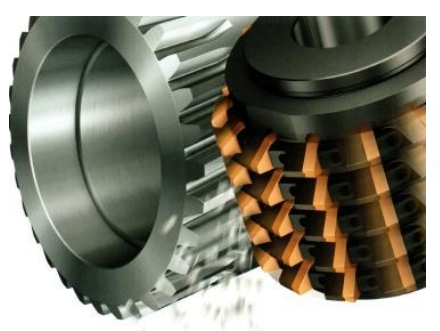

b)

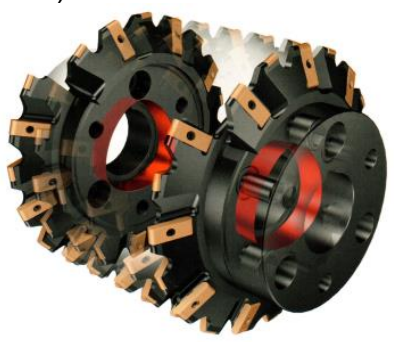

Fig. 15. Folding recess milling cutters: a) machining of a toothed wheel, $b$ ) segmented milling cutter (Sandvik)

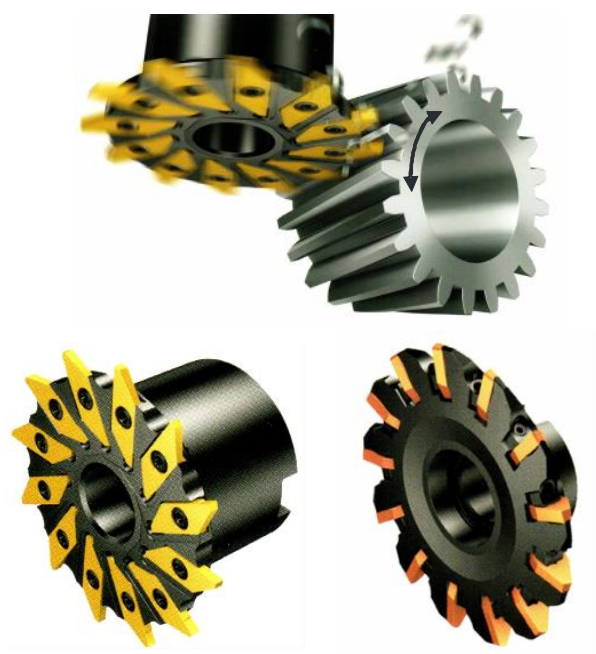

Fig. 16. Milling of gear wheels by InvoMilling method and exemplary disc tools (Sandvik)

The design possibilities of machine tools and their control have developed so much that you can now shape your teeth with enveloping cutters on turning centers, which is part of the complete machining trend. Universal CNC milling machines also have more and more possibilities to shape their teeth. A number of constructions of folding tools have been created, for example, disc milling cutters, for gear machining of gears. In order to be able to use such a treatment, it was necessary to extend the kinematic capabilities of machine tools and develop programs that generate envelope movements. Thus, where large-scale gears are not produced, they can be shaped on universal machines.

The emergence of the need for efficient machining of gears, especially with large modules, has resulted in the creation of modified and combined technologies for their shaping. Sandvik and DMG MORI have developed the InvoMillingTM technology, which uses - instead of the envelope screw cutters - simple folding disc cutters and the creation of a special software to control the operation of CNC milling machines (fig. 16). At the first stage of shaping, rough edges of interdental grooves are machined with a shaping method, and in the second stage, the sides of the teeth are machined more precisely by the enveloping method.

Currently, it is possible to make this wheel with straight and oblique teeth with modules in the $1 \div 12 \mathrm{~mm}$ range, as well as spline and cone tooth with straight teeth. One of the advantages of this technology is that you do not use special tools. Standard disc tools allow you to shape the contours of the teeth with different modules. The condition is to have a five-axis CNC milling machine and InvoMilling ${ }^{\mathrm{TM}}$ software.

Another technology - uP-Gear - was introduced by Sandvik. It consists in the fact that for various phases of roughing of teeth, especially those with large modules, various tools from the group of disc cutters are used. Each of them shapes a different area of the root (fig. 17).

The great possibilities of CNC milling machines have resulted in new outlines of teeth, for example conical wheels with a sinusoidal tooth line. Gears with such an outline allow for transferring significantly, by about $30 \%$, higher torques. Despite the higher price, they can be successfully used where mass or small dimensions of the structure play a key role.

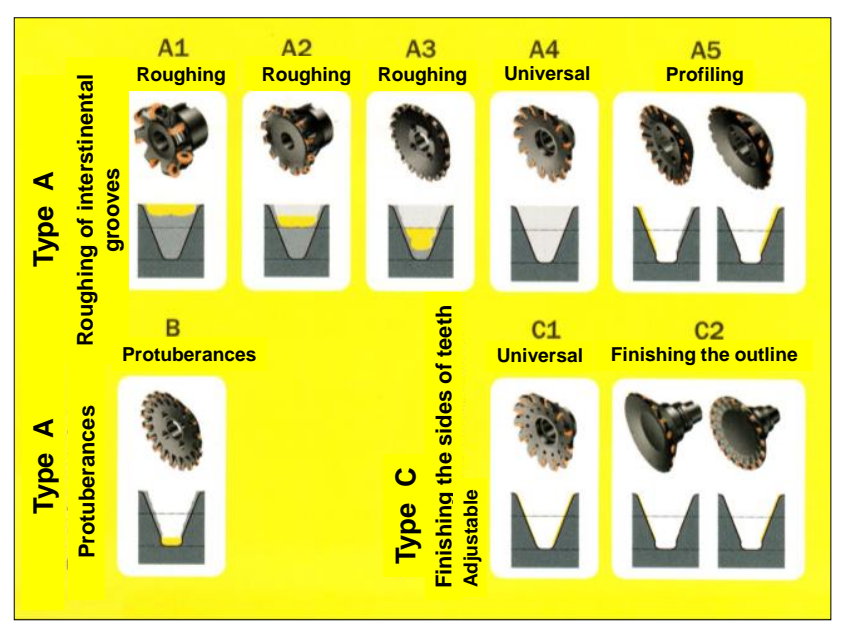

Fig. 17. Classification of tools for machining of gears by the uPGear method (Sandvik)

\section{Diagnostics and supervision}

Globalization of production, transfer of production to countries with low production costs as well as more and more expensive means of production cause that one of the ways of maintaining the competitiveness of domestic production is further automation of processes.

In the case of cutting, one of the main motivations for monitoring is the willingness to use the full cutting capabilities of increasingly expensive tools. If the tool wear status is not diagnosed on an ongoing basis, it should be changed in advance, after the so-called a period of reliable 
work. This period is significantly shorter than the actual shelf life. And although, for example, $95 \%$ of the tools could continue to work, they should be replaced just in case, so there would be no shortages or disruptions in production. This generates significant financial losses.

Therefore, in reputable factories, in mass production, most of the machine tools for cutting are already equipped with systems that supervise the work of the tools. Although they are expensive, require highly qualified personnel and complicate the technological process (especially if it is frequently changed) or adjustments, it pays for itself.

The degree and scope of the automation of production is successively achieved due to:

- development of sensors enabling more accurate, more reliable identification of hazards to processes,

- increasing the response rate to interruptions in the cutting process with increasing speed and dynamics, in which the effects of machining irregularities, e.g. collisions, are more and more expensive,

- development of systems and procedures of automatic reaction to process disruptions and their prediction,

- greater speed, correctness and effectiveness of actions to prevent failures and downtime of the machining process.

\section{New cutting strategies}

New technical possibilities create grounds for significant improvement in the broadly understood production efficiency. This is particularly noticeable in the case of milling, where it is often necessary - as a result of shortening the production series, as well as high strength requirements of products (e.g. for the aviation industry) shaping of objects made of solid material.

A very long time ago high cutting technologies (HSC) appeared, and a bit later - high productivity (HPC) cutting, in which the cutting speed was slightly reduced compared to HSC, in order to extend the tool life, but the other machining parameters were increased. This resulted in significantly higher performance at the cost of slightly lower accuracy. Thus, HPC is used in bending and shaping, and HSC - in finishing.

Another trend that is gaining importance is cutting with large feeds. This technique appeared in the fifties of the last century in the USSR in turning thanks to the use of Kolesov knives. Half a century later, it was reborn in a slightly modified version with the use of Wiper blades. Blades with a "truncated" corner allowed for a much lower roughness compared to the blades with classic corners, or for a significant increase in feeds while maintaining the same roughness. The efficiency of using Wiper blades significantly increased for large feeds.

This type of machining also has its drawbacks, e.g. - difficulty in automating the generation of tool path correction taking into account the shape of the corner (but it is possible in the case of traditional blades with any radii $r_{n}$ ), - necessity of correcting the tool path, if the cutting takes place at an angle in relation to the axis of rotation of the object,

- shape distortions occurring in the treatment of curved surfaces,

- increased cutting resistance, which may affect the accuracy of machining,

- uneven roughness of shaped surfaces during variable cutting directions.

Another reason for the increased interest in machining with large feeds was the ability to achieve relatively high milling performance for significant tool overhangs, such as when forming deep pockets and machining hard-to-reach places. Specially shaped edges (fig. 18) on the end faces of the cutters and small depths of cut caused that the resultant force acts on the milling cutter and the machine spindle not perpendicularly, but along their axis of rotation. In this direction, the stiffness of the system is much larger than in the radial direction, which translates into lower vibrations and deformations and allows for increased cutting performance.

This quite effective treatment will become more important in the future, as the techniques for manufacturing semifinished products are being developed by casting, forging and incremental methods. Progress in this area means that the finishing allowances for finishing treatments will be smaller and smaller. For small oversize, it is possible to increase the machining efficiency by increasing feeds.

In cutting technology with high feeds, the shape of the cutting edges changes - they initially had large rounding radii (fig. 18 and fig. 19), which required separate plates, now they are linear edges of standard plates, inclined at a small angle (fig. 20).

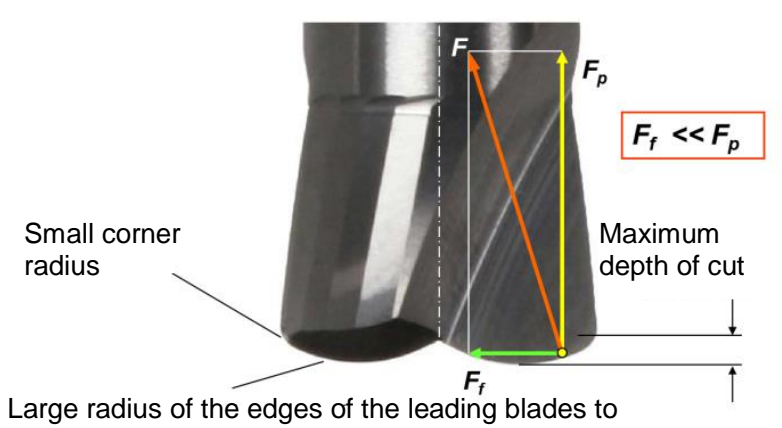

smooth unevenness after a large feed

Fig. 18. Concept of constructing milling cutters with large feeds [16]

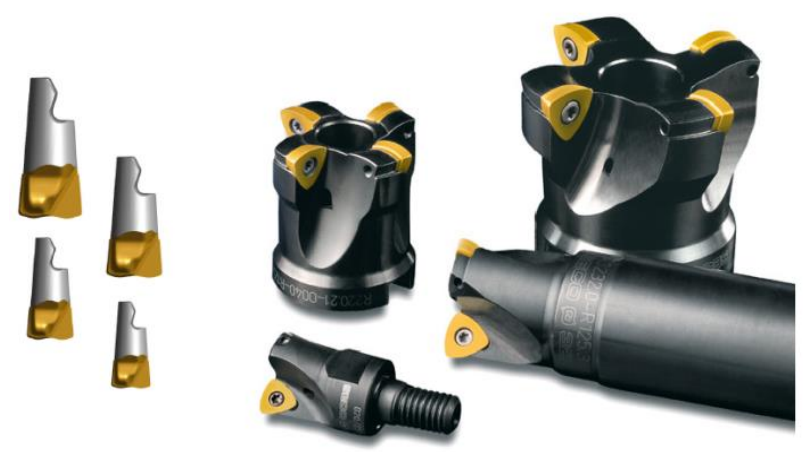

Fig. 19. Examples of heavy feed cutters (SECO)

There is a growing interest in deep milling, kinematicslike drilling in incomplete material. When choosing deep pockets, often at great depths that require considerable tool overhangs, this milling has a number of advantages over classic face milling.

As in milling with large feeds, the cutting forces are directed to the greater extent along the spindle axis, and in a smaller direction - in the perpendicular direction. As mentioned, in this direction the tool-spindle system is stiffer, which allows to increase the permissible load of the tool, more stable operation and allow for increased productivity.

Therefore, the reason for using high feeds and plunge milling is similar. The difference is that small feeds are machined with large feeds, and deep - large volumes of material are removed. The main disadvantage of these 
shaping methods is the very roughly machined side surface of the part walls, which require a later, already classical, peripheral finishing treatment. However, one can expect to reduce the processing time of deep pockets by up to $50 \%$.

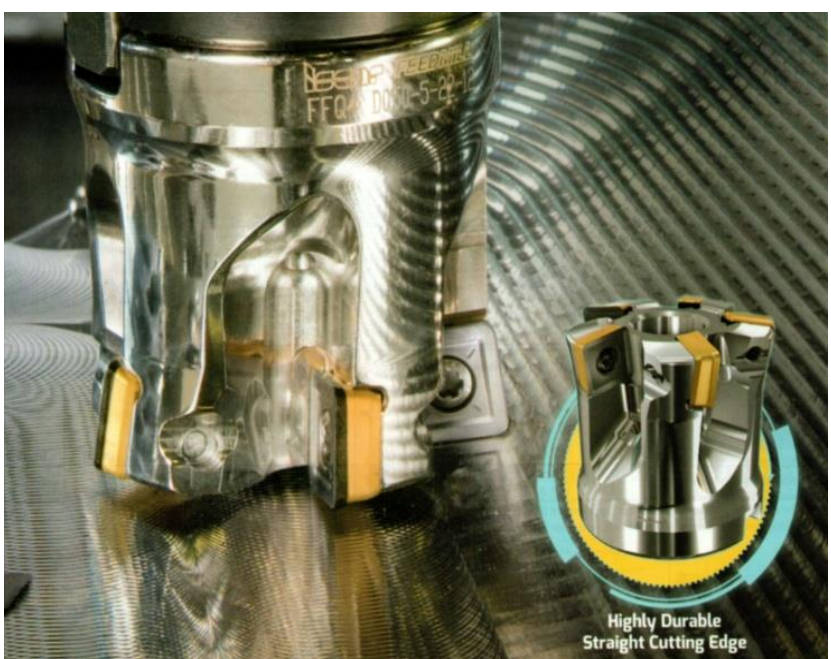

Fig. 20. Cutter with large feeds (Iscar)

From the elements of the technological process, the reduction of its time is the most effective in reducing production costs. Therefore the hard machining technology has emerged. Shortening the product development time was achieved by eliminating the heat treatment and transport associated with it.

In addition, there is no hardening deformation in this technology so you do not have to remove them with abrasive machining. The quality of surface hardened after machining is very high and in many cases no abrasive finishing treatment is required.

One of the main limitations in the use of high speed machining and hard machining is the limited durability of the tool. This is due to the high cutting temperature. That is why the trochoidal cutting technology appeared (fig. 21), in which the cutting angle of the cutter was reduced to significantly, even by half, lower this temperature. In this way, the cutting efficiency of this technology has been increased.

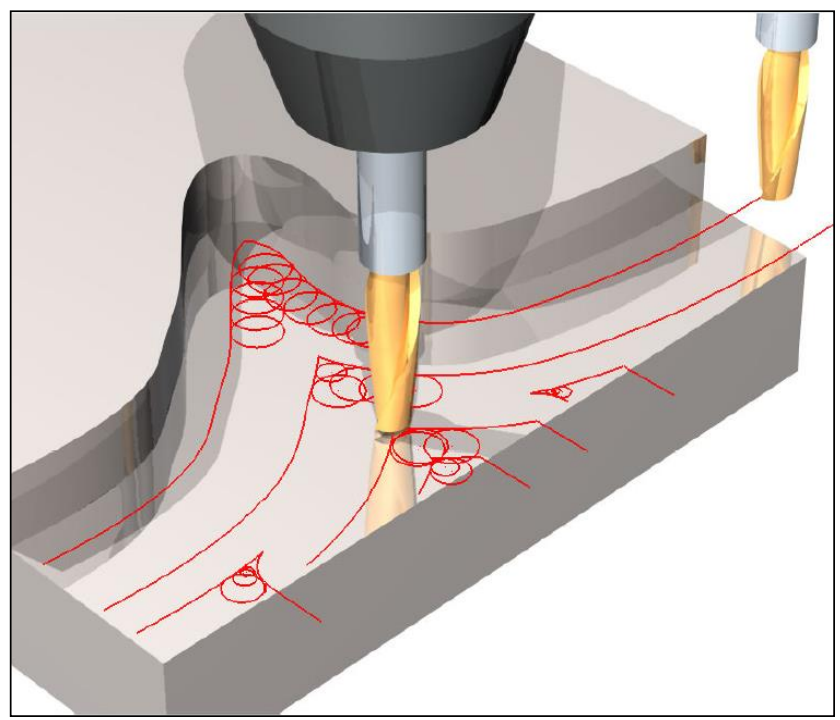

Fig. 21. Example of designed milling tracks during trochoidal milling [16]

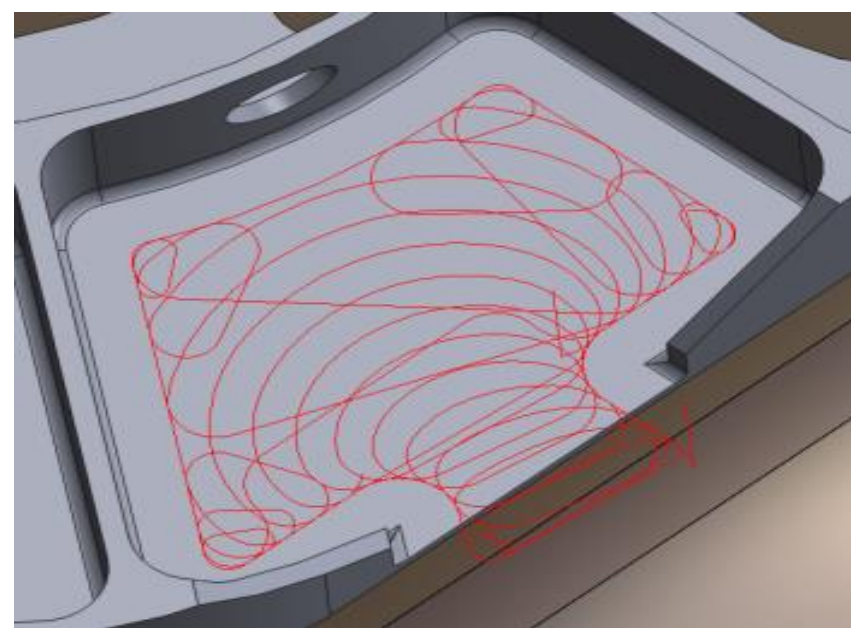

Fig. 22. An example of a tool path generated by iMachining technology during pocket machining

There have been many variations of this treatment, in which the tool paths deviate even quite significantly from the trochoids, although they are still called so.

An interesting modification of the trochoidal tool path is iMachining technology, patented by SolidCAM. The assumptions of this technology [17] consist in providing a quasi-permanent tool load and removing at least $65 \%$ of the allowance during continuous contact of the tool with the workpiece.

The iMachining program generates the tool path (fig. 22) to ensure its constant load, which also sometimes requires changing the feed sizes. Maintaining a constant local milling width allows stabilizing the operating temperature at an appropriate level and prevents overheating of the blades. Despite the relatively high price of the software, such technologies allow for a much higher yield and a significant extension of the tool life, which translates into an increase in the machining efficiency.

\section{Tool change time}

In the quest to increase machining efficiency, the shortening of unproductive machine tool downtimes will play an increasingly important role [1]. Some machines already achieve automatic tool change times less than a second. This dynamics can be effectively used also when replacing a worn tool with new or regenerated tools, if you have sister tools in the machine magazine, precisely set to size or with precisely defined corrections, which are then, e.g. automatically, loaded into the machine's control system.

It seems that this approach to automation will be dominant in the future. If for various reasons it is not possible to rationally apply automatic or largely automatic tool change, the alternative is to carry it out so that the downtime is as short as possible. In such cases it is advantageous to replace the blade itself, especially when the repeatability of the positions of its corners and edges is so large that it is not necessary to make a time-consuming re-setting of the tool and to determine the correction of its positions. This seems to be another reason for replacing the hyperbolic tools - foldable (figs. $2,15,16)[1,10]$.

\section{Hybrid technologies}

Higher and higher requirements regarding the product's dimensional accuracy and trends, as well as tendencies to shorten the production series in favor of their diversity, 
create pressure on the creation of technologies and hybrid machine tools, combining the advantages of several shaping methods.

It is no longer about, for example, advanced machining centers based on CNC lathes on which, in addition to turning, can be milled, drill oblique holes, cut teeth, chisel grooves, use abrasive machining, etc. Such machine tools, equipped with modules or mechatronic tools, admittedly significantly expand possibilities of shaping products, but due to their high versatility they are not very efficient.

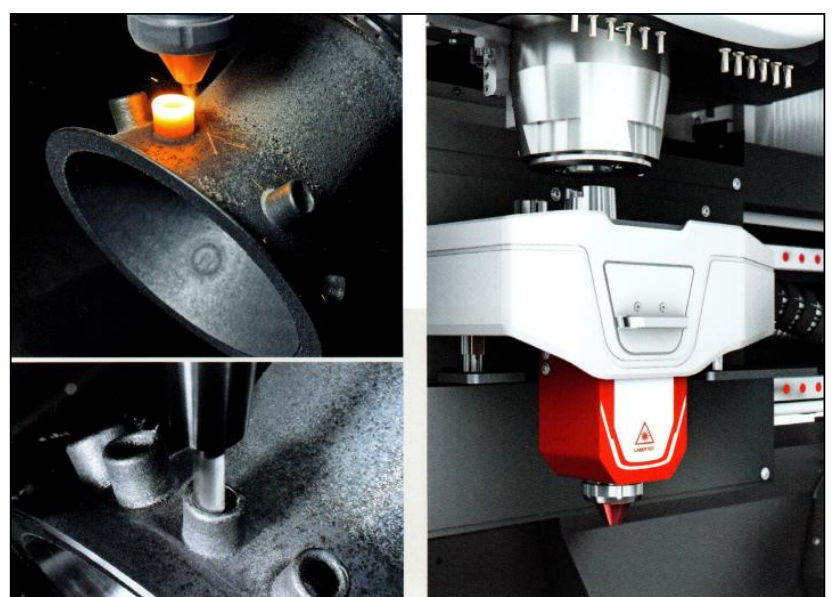

Fig. 23. Example of combining generative techniques (3D printing) and machining (DMG MORI) in one machine

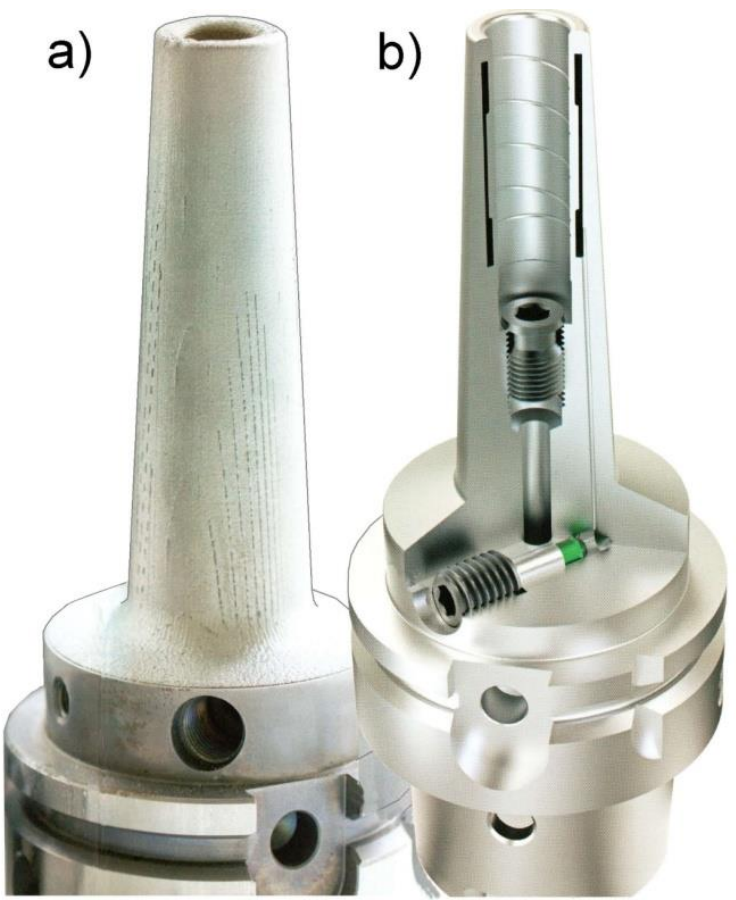

Fig. 24. Examples of bodies of hydraulic holders printed with 3D technique: a) printed part to the grip part, $b$ ) section of the frame after execution (MAPAL)

Hybrid machines are, for example, constructional solutions for lathes and milling machines, lathe-grinders, etc. Recently, machine tools have been introduced that combine machining, abrasive machining, electro-erosion and electrochemical drilling. Often, these techniques are supported by vibrations and various energy sources. The incorporation of generative techniques into one productive system becomes more and more important (fig. 23 and fig.
24). The latter are used repeatedly and alternately during the production of one object in one fastening. This type of device considerably extends the possibilities of shaping very complex products.

Hybrid machine tools also allow the dissemination of socalled complete machining, i.e. shaping and even assembly of the entire product takes place in one operation. The item is made without or with as few repetitions as possible. This results in increased efficiency and a significant improvement in the machining accuracy, especially on surfaces that are dimensionally coupled with tight tolerance fields.

The possibilities of configuring hybrid treatments are very wide, especially if you combine different energy sources. The synergy of their mutual interactions is often obtained. This is particularly advantageous for hard-to-machine materials and hard-to-shape objects. Currently, the scope of these technologies is not very wide and is usually limited to the production of complex prototypes, as well as forms and tools for serial replication of objects, mainly used in nanotechnologies. This is due to the significant costs of these technologies and not yet very high performance. It seems that due to the many advantages of these techniques, as well as the better understanding of production capabilities, the area of their application will expand.

An extensive overview of hybrid treatments, with an attempt to unify definitions and terminology, is in [5].

The use of generative techniques in the production of tool bodies (fig. 7b) or tooling tools, such as hydraulic holders, is growing (fig. 24). Thanks to the large possibilities of these technologies, frames can also be made for fixing tools with very small diameters, even on the order of a few millimeters [12].

\section{Conclusions}

As a result of changes related to the introduction of production 4.0, it is predicted that in Europe itself, in the near future, it will have to change its qualifications from several to several million employees. More comprehensive computerization of almost all production means and management systems will cover production techniques even more widely. The pursuit of computer aided at every stage of production, including during the development of technologies, with more and more advanced procedures optimizing them is observed.

Leading global tool companies offer access to electronic data, most often placed on websites, information and procedures that may be important in the selection of a tool for technological operation, helping in the selection of parameters and processing conditions. In many cases, you can calculate the processing time, and sometimes also calculate the costs of the operation.

Despite considerable progress in the production of lightfree and even incremental manufacturing techniques that allow the delivery of more and more precisely manufactured blanks, machining and abrasive machining continue to play a key role in production. This is due to their greater accuracy, process stability and the ability to obtain the required, increasingly high quality surface layer of the shaped surface, sometimes including a very sophisticated geometric structure of its topography, own stresses and strengthening.

It is also necessary to notice in recent times a significant reappraisal of the concept of "technological construction". What was once considered to be extremely non- 
technological, because it was difficult or impossible to implement, today, due to the new shaping possibilities offered by machine tools and tools, including controlled and mechatronic tools, can become a technological solution.

\section{REFERENCES}

1. Cichosz P. „Efektywność kształtowania przedmiotów osiowosymetrycznych w zintegrowanym wytwarzaniu". Wrocław: Oficyna Wyd. Politechniki Wrocławskiej, 1998.

2. Cichosz P., Kuzinovski M. „Sterowane $i$ mechatroniczne narzędzia skrawające". Warszawa: PWN, 2016.

3. Cichosz P., Kuzinovski M., Tomov M. „Narzędzia skrawające z materiałów supertwardych. Cz. I. Ostrza diamentowe". Mechanik. 8-9 (2017): pp. 660-671; Cichosz P., Kuzinovski M., Tomov M. „Narzędzia skrawające z materiałów supertwardych. Cz. II. Ostrza z regularnego azotku boru". Mechanik. 10 (2017): pp. 819-824.

4. Cichosz P., Kuzinovski M., Tomov M., Urych A. „Zaokrąglanie krawędzi skrawających ostrzy z węglików spiekanych". Mechanik. 7 (2018): pp. 458-462.

5. Grzesik W. „Hybrydowe procesy obróbki ubytkowej. Definicje, zasady tworzenia i znaczenie w przemyśle". Mechanik. 5-6 (2018): pp. 338-342.

6. Grzesik W. Advanced Machining Processes of Metallic Materials". Amsterdam: Elsevier, 2017.

7. Lauwers B., Klocke F., Klink A., Tekkaya A.E., Neugebauer R., Mc Intosh D. „Hybrid processes in manufacturing”. Annals of the CIRP Manufacturing Technology. 63, 2 (2014): pp. 561-583.

8. Information materials from DMG MORI.

9. Information materials from Gühring.

10. Information materials from Iscar.

11. Information materials from Komet.

12. Information materials from Mapal.

13. Information materials from Mitsubishi.

14. Information materials from Novator $A B$.

15. Information materials from Sandvik Coromant.

16. Information materials from SECO.

17. Information materials from SolidCAM.

18. Information materials from TIZ Tools.

19. Rösiger A., Goller R. „Stand der Technik bei der Bearbeitung von CMCs". Sitzung der AG Endbearbeitung des CCeV Ceramic Composites. Augsburg (20 November 2015).

Translation of scientific articles, their computer composition and publishing them on the website www.mechanik.media.pl by original articles in Polish is a task financed from the funds of the Ministry of Science and Higher Education designated for dissemination of science.

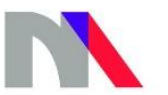

Ministry of Science and Higher Education

Republic of Poland 